Original Article

\title{
Sedative antistress activity of ultra high dilutions of fish skin containing alarm pheromone on hydrobionts in comparison with warm blooded animals.
}

\section{Tomkevich M.S.}

National Association for Traditional and Complementary Medicine. E-mail: mtomkevich@gmail.com

\begin{abstract}
Background: A potentiated preparation of carp skin was used to study its effect on fish and other organisms. It is known that the skin of any kind of fish contains an alarm pheromone, possessing a species-specific effect of high sensitivity about $10^{-7} \mathrm{~g} / \mathrm{l}$.
\end{abstract}

Aims: The aim of the present study was to analyze the biological action of high diluted preparation of pheromone-rich carp skin on the stress dynamics of various species. This work was conducted on infusoria, carps, rainbow trout, and white outbreed laboratory rats. These species were used to study behavior and stress markers under the influence of carp skin homeopathic dilution D15. This preparation conventionally called Pyscin was patented in 2000 y in the Russian Federation (patent №2156571).

Methodology: 1) The spontaneous motility of infusoria with help of light microscope technique was studied through the registration number of intersections of the viewfinder eyepiece of the binocular microscope. This activity wasstudied before and 60 minutes after the exposure in test solution 1 . Test solution 1 was prepared by adding $0.1 \mathrm{ml}$ of Pyscin to $10 \mathrm{ml}$ of water. 2) Several physiological markers of stress in vivo (hepgglopin incytaneous mucus, the average red blood cell volume in blood, hemoglobin content ip esy nrocyte) $N$ ( studied applying the test strip express method. The test solution 2 was made by adding Pyscin $10 \mathrm{ml}$ to $10 \mathrm{~L}$ of water. Fish were divided in the three groups -an intact control group, stressed by the handling group and then replaced in the water, and the third group stressed by handling and then placed in the water containing test solution 2. 3/Horizontal spontaneous moving activity of the rats was studied in the "open-field" method by registering the number of intersections of the central line of a special camera. The study was carried out before and 60 minutes after the oral administration of $1 \mathrm{ml}$ of test solution 3 (Pyscin D30).

Results: The study shows the decrease of spontaneous infusoria motility by $27 \%(\mathrm{p}<0.01)$ and horizontal motor activity of the rats by $32 \%(\mathrm{p}<0.01)$. The content of hemoglobin in the cutaneous mucus in fishes (carp, rainbow trout) under stress was increased by $49 \%$ in comparison with the control intact group and was unchangeable under the influence of Pyscin. Handling increased the average red blood cell volume by $14 \%$, hemoglobin content in erythrocyte - by $31 \%$ these parameters didn't change under the influence of Pyscin $(\mathrm{p}<0.01)$. 
Conclusion: The obtained results can be interpreted as the sedative and antistress anxyolitic effects of Pyscin used in high dilutions. This effect is universal for various species.

Keywords: antistress effects, alarm pheromones, aquatic animals, rats, infusoria, moving activity, biochemical stress parameters for fish.

Received: March 1, 2018. Accepted: April 26, 2018.

(C) International Journal of High Dilution Research. Not for commercial purposes. 